\title{
Anxiety Levels in Children with Autism Spectrum Disorder: A Meta-Analysis
}

\author{
Francisca J. A. van Steensel ${ }^{1}$ - Emma J. Heeman ${ }^{2}$
}

Published online: 20 March 2017

(C) The Author(s) 2017; This article is published with open access at Springerlink.com

\begin{abstract}
The aim of the current study was to metaanalytically examine whether anxiety levels in children with autism spectrum disorders (ASD) are elevated. A total of 83 articles were selected from a systematic literature search and were included in the meta-analyses. Results demonstrated that children with ASD had higher anxiety levels compared to typically developing children, and this difference increased with IQ. Youth with ASD also tended to have higher anxiety levels compared to clinically referred children, and this difference increased with age. Children with ASD had higher anxiety levels compared to youth with externalizing or developmental problems, but not when compared to youth with internalizing problems. The study findings highlight the importance of more research in order to fully understand the nature and development of anxiety in children with ASD. More specifically, the results suggest that especially high-functioning adolescents with ASD may be at risk for developing anxiety disorders. Therefore, it seems important to carefully follow and monitor children with ASD transcending to adolescence.
\end{abstract}

Keywords Autism $\cdot$ Anxiety $\cdot$ Children $\cdot$ Meta-analysis

Francisca J. A. van Steensel

f.j.a.vansteensel@uva.nl

1 Child Development and Education, University of Amsterdam, Research priority area Yield, Nieuwe Achtergracht 127, 1018 WS Amsterdam, Netherlands

2 De Opvoedpoli B.V., Dorpstraat 145, 2712 AG Zoetermeer, Netherlands

\section{Introduction}

Youth with autism spectrum disorders (ASD) are characterized by deficits in social communication and by the presence of restricted interests and repetitive behaviors (APA 2013) but also frequently endorse comorbid symptoms of anxiety, depression, attention and behavior problems (e.g., Gadow et al. 2005; Goldin et al. 2014). Indeed, comorbid disorders are commonly observed in youth with ASD (e.g., de Bruin et al. 2007; Leyfer et al. 2006; Simonoff et al. 2008). Anxiety disorders seem to be one of the most common conditions and are meta-analytically estimated to be prevalent in about $40 \%$ of youth with ASD (van Steensel et al. 2011). This prevalence rate is thought to be higher compared to typically developing children in which prevalence rates up to $27 \%$ are reported (Costello et al. 2005). In addition, studies comparing anxiety levels of children with ASD to those of typically developing children consistently demonstrate higher anxiety levels for children with ASD (e.g., Kuusikko et al. 2008; Park et al. 2014). However, a systematic (meta-analytical) approach of the size of this difference is currently lacking and therefore we do not know exactly how large this difference is. Similar, there are suggestions that youth with ASD are more prone to anxiety than youth from (some) other clinical groups (e.g., see review of MacNeil et al. 2009), but, again, the size of the possible difference is unknown.

Next to the lack of knowledge about the size of the difference in anxiety between ASD samples and typically developing or clinical samples, it is important to examine which variables may be associated with this difference. For example, the size of the difference may depend on the type of comparison group. Joshi et al. (2010) compared children with ASD to a mixed clinical sample and found that children with ASD were more likely to endorse anxiety disorders (among other disorders). In addition, youth with 
ASD were found to be more prone for anxiety disorders compared to youth with externalizing disorders; i.e., ADHD (Park et al. 2013; Van Steensel et al. 2013) or conduct disorder (Green et al. 2000; Pugliese et al. 2013). However, when compared to anxiety-disordered children, results are less clear. Farrugia and Hudson (2006) did not report differences between children with ASD and clinically anxious children (child and parent report were aggregated), while Russell and Sofronoff (2005) did find children with ASD to have higher levels of anxiety according to parent report. Further, van Steensel et al. (2012) found that parents reported higher anxiety symptoms (total, specific, social, generalized and panic anxiety) for children with ASD compared to clinically anxious children, however, child report did not reveal any group differences except for specific phobias. Thus, next to the type of comparison group, type of informant (e.g., parent, child, teacher, clinician report) may be an important factor to consider. Other factors of interest are age and IQ. It is known that anxiety tends to increase with age in general, and it seems that the prevalence of anxiety disorders in youth with ASD follows a similar developmental course (van Steensel et al. 2011). However, what is not known is whether the difference in anxiety levels between children with ASD and typically developing children, or between children with ASD and clinically referred children, is the same or different across developmental phases. The same applies for IQ, which may be even more complicated because the relation between IQ and anxiety in youth with ASD is not clear itself. That is, some studies found a positive association between IQ and anxiety (e.g., Gadow et al. 2005; Eussen et al. 2013), while others point to a negative association (e.g., White and Roberson-Nay 2009) or suggest a quadratic instead of a linear relation (van Steensel et al. 2011).

The aim of the current study was to meta-analytically estimate the difference in anxiety levels between children with ASD and typically developing children, and between children with ASD and clinically referred children. As previous studies point to different findings, and results seem to be depending on the type of comparison group and informant, additional analyses were conducted for the different comparisons groups (internalizing, externalizing, and other problems) and informants (parents and children). Further, the moderating influence of age and IQ was examined by including these variables as moderators.

\section{Method}

\section{Literature Search}

The literature search was conducted in two phases. The first phase covered articles published till the half of 2010 leading to a selection of 86 studies that reported about an ASD sample and an anxiety measure (procedure and results of this first phase are reported in van Steensel et al. 2011). The second phase of the literature search covered the period 2010 till 2016. The same approach for the literature search was used as in the first phase: the words "Autism" "High Functioning Autism" "Asperger" "Pervasive Developmental Disorder" "PDD" were used in combination with "Anxiety" "Anxious" "Anxiety Disorder" "Comorbidity" "Comorbid disorder" "Psychological disorder" and "Psychiatric disorder", within the following databases: 'PsychInfo', 'Pubmed', 'Web of Science' and 'ERIC'. During both phases, abstracts were screened for relevance and got selected if they reported about (1) an ASD sample and (2) a measure assessing anxiety problems (which did not explicitly needed to be mentioned in the articles; e.g., measures assessing comorbidity were also selected at this point). During the second literature search, 7332 abstracts were screened of which over $10 \%$ was screened by both authors (agreement between the authors regarding the selection of articles was over $98 \%$ and in case of disagreement articles got fully screened). Full articles $(N=184)$ were then screened and included in the meta-analysis if (1) an ASD sample and a comparison group was included, (2) anxiety was measured by a standardized questionnaire, (3) a mean age $<19$ years was reported, and (4) articles were published in English. Studies were excluded if (1) they did not report on empirical data (i.e., articles were reviews), (2) they reported about case studies only, (3) other informant reports than child or parent (e.g., only teacher report) was used, or (4) they used an interview (measuring anxiety disorders) instead of a questionnaire (measuring anxiety levels). The later exclusion criteria was based on the dimensional focus of the current meta-analyses (instead of the focus on a categorical approach as was done in van Steensel et al. 2011). A total of 83 studies were found to meet the criteria and were selected for the current meta-analyses (see Table 1).

\section{Coding}

Mean age, mean IQ, informant (child and/or parent) and comparison group was coded for all studies (see Table 1) by the authors of the study, and a graduate student double coded $10 \%$. The interrater agreement was excellent (above .90). For analyses, the comparison group was divided into: (1) typically developing children, and (2) clinically referred children. The clinical comparison group was further subdivided in: (2a) internalizing problems (anxiety and/or mood problems), (2b) externalizing problems (ADHD, oppositional defiant disorder, and/or conduct disorder), (2c) developmental problems (e.g., Down-Syndrome, Fragile X, intellectual/language disabilities, learning problems), or (2d) clinical not otherwise specified (mixed clinical sample 


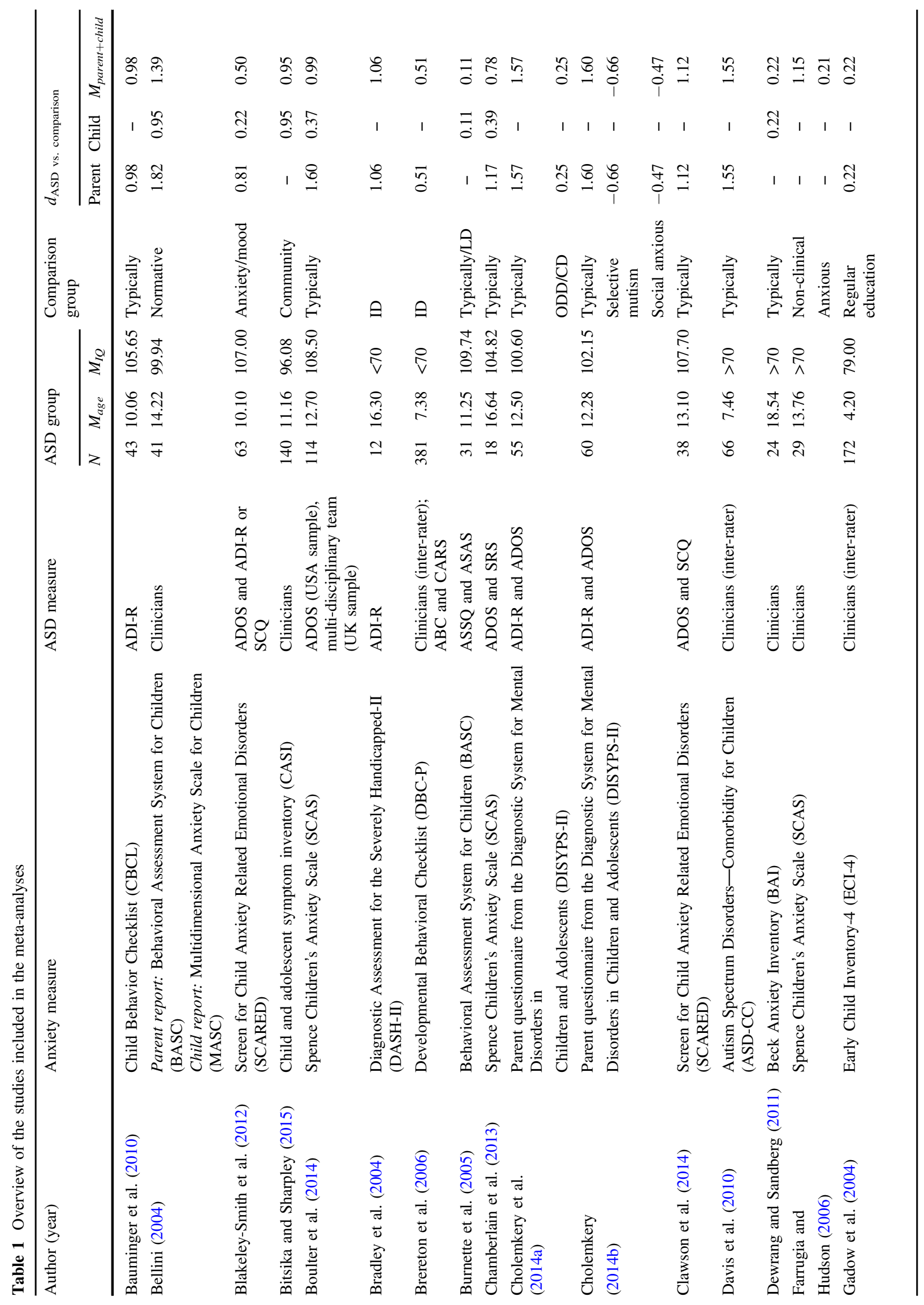




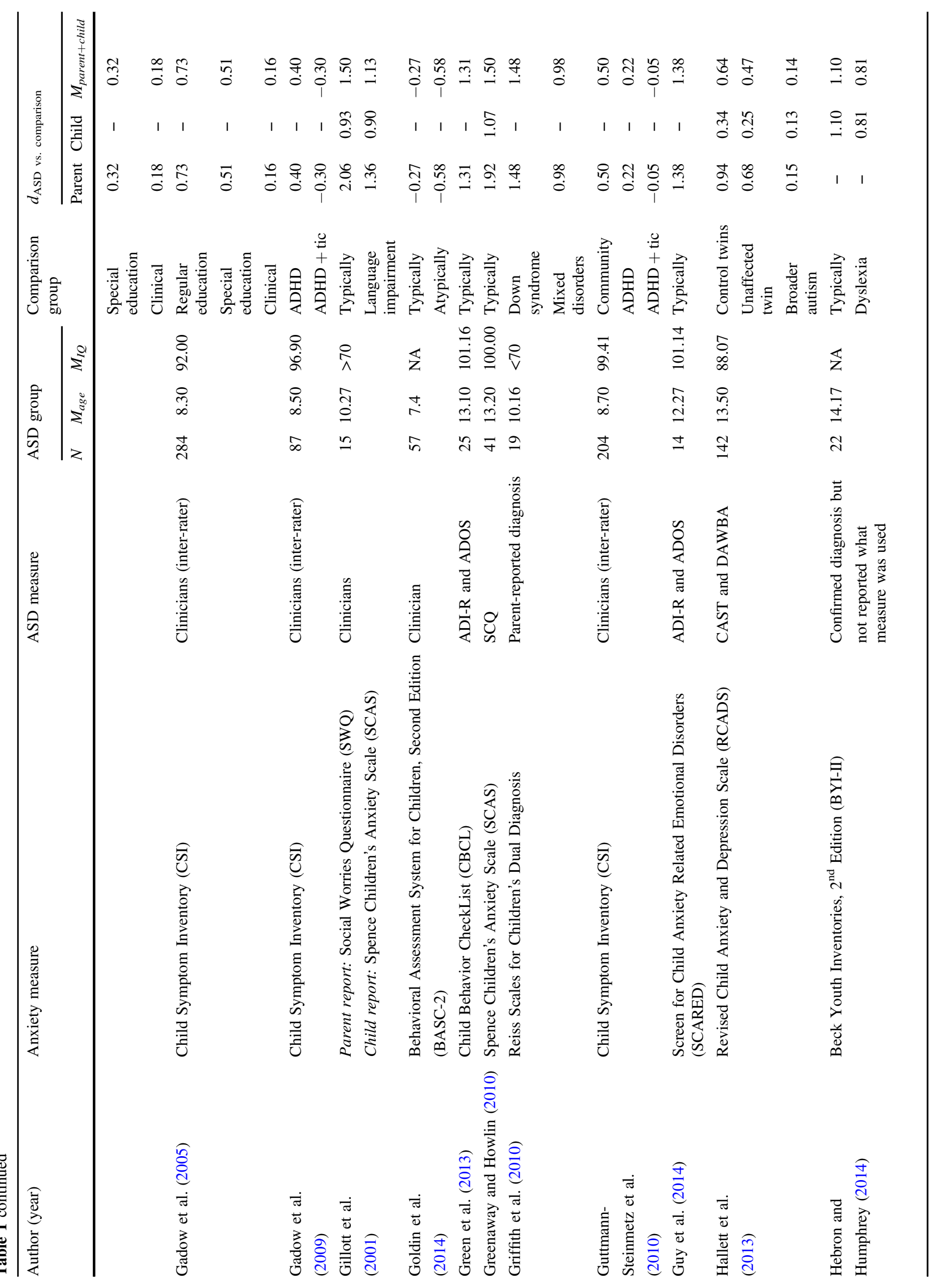




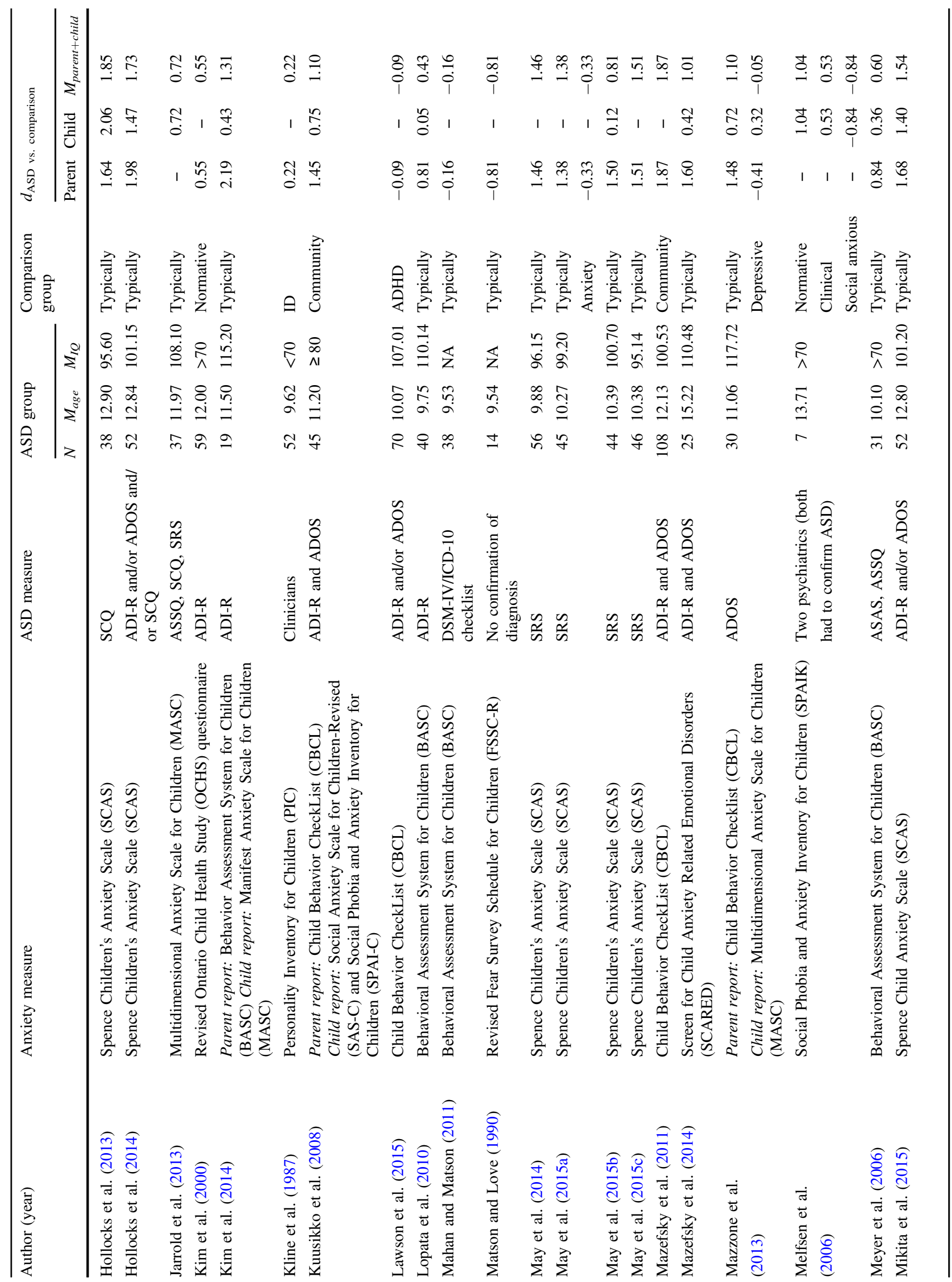




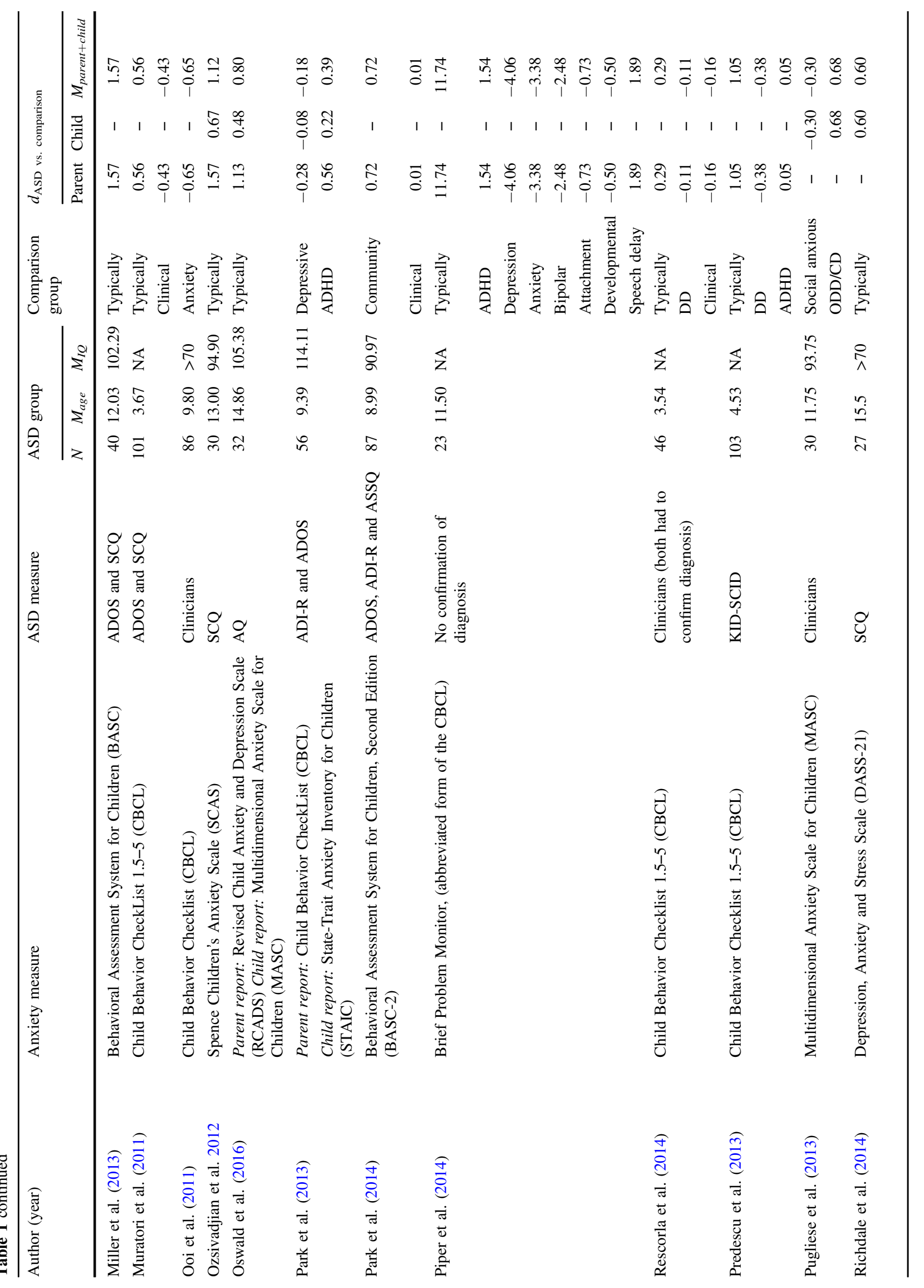




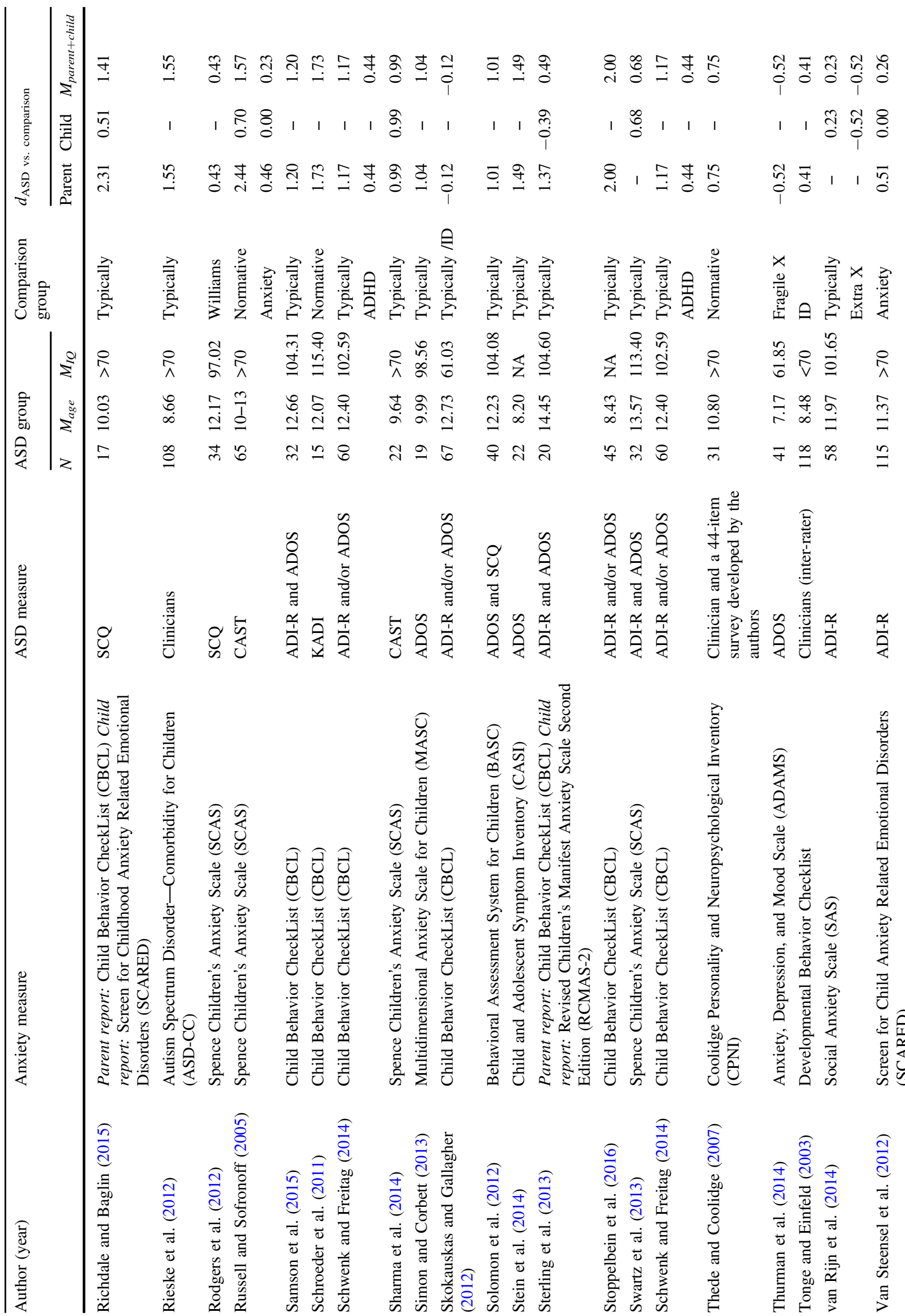




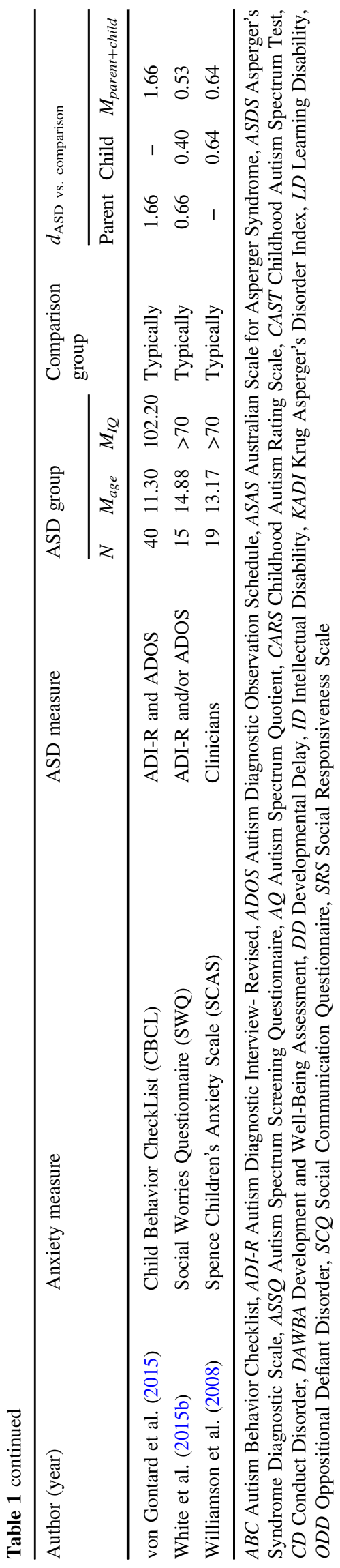

or special education sample). Two studies (Burnette et al. 2005; Skokauskas and Gallagher 2012) used a mixed sample consisting of typically developing children as well as children with learning/intellectual disabilities and were therefore registered as having both a typically developing as well as a clinical comparison group.

For all studies an effect size (Cohen's $d$ ) of the difference in anxiety levels between the ASD sample and the comparison sample was calculated by the authors of the study. If both parent and child report was used, a separate effect size for parent report and for child report was calculated. However, for the main analyses, a mean of the parent and child effect size was taken to represent an average effect size for that study. The rationale for aggregating child- and parent report was that there are many studies suggesting to use multi-informant reports for measuring childhood anxiety, and that-while child-parent agreement is only modest at best (also in non-ASD samples)_child report, in addition to parent report, may provide important information from another perspective (e.g., Brown-Jacobsen et al. 2011; Comer and Kendall 2004; Grills and Ollendick 2003). Furthermore, we reasoned that the aggregation of child-and parent reports would result in a best-estimate of the 'real truth' because whereas children with ASD may underreport their anxiety levels (e.g., due to disabilities in insight), parents may over-report anxiety levels of their children (e.g., due to being unable to disentangle anxiety symptoms from ASD symptoms) (van Steensel et al. 2011). Finally, the aggregation of child- and parent reports allowed for a larger number of studies to be included in the analyses (which was particularly needed to compare the ASD sample to the specific comparisons groups). A similar approach of aggregation was used when multiple comparison groups were used in a single study: i.e., effect sizes between the ASD sample and each of the comparison groups were calculated separately and then a mean of these effect sizes was taken to represent an average effect size of that particular study. In addition, some studies used (part of) the same ASD sample in multiple studies (e.g., Cholemkery et al. 2014a, b). In those cases, a mean effect size of the overlapping studies was calculated and entered in the meta-analysis.

When multiple measures in a study were used to assess anxiety; (1) a total anxiety score was chosen over a specific anxiety score (e.g., social anxiety or generalized anxiety), (2) questionnaires measuring anxiety were preferred over a general problem behavior questionnaire, however, (3) a total anxiety score of a general problem behavior questionnaire was preferred over a specific anxiety score (e.g., a questionnaire measuring social anxiety only). Some studies reported about specific anxiety scores only (i.e., no total anxiety score but only subscale scores for social anxiety, generalized anxiety etc.) and in those cases, a mean effect size was calculated from the specific anxiety scores. 


\section{Outliers, Normality and Publication Bias}

For the two main analyses (ASD compared to typically developing and ASD compared to clinical), normality, outliers and publication bias was examined. Using standardized Z-scores, one outlier was identified in the analyses comparing youth with ASD to typically developing children. This outlier was adjusted in the highest score not being an outlier. Normality was explored with the Kolmogorov-Smirnov test, and no violations were found. Publication bias was examined by statistically testing for funnel plot asymmetry with the rank order correlation coefficient, the Egger's regression method and by adding the standard error as a moderator to the random effect model. All methods revealed non-significant results.

\section{Analyses}

Two main meta-analyses were conducted: (1) ASD vs. typically developing children, and (2) ASD vs. clinically referred children. The aggregated parent + child effect sizes were used for these analyses. Moderator analyses were conducted for both meta-analyses with mean age and mean IQ entered as predictors. In addition, separate meta-analyses were conducted for parent and child report, and for the different comparison groups (internalizing problems, externalizing problems, developmental problems, and clinical not otherwise specified). The SPSS macro's of Lipsey and Wilson were used for analysis, and homogeneity across studies was examined with Q statistics.

In meta-analyses, both fixed as well as random models can be conducted. Hedges and Vevea (1998) argue that while in some cases the choice for either model is led by the homogeneity (or heterogeneity) of the effect-size parameter (i.e., fixed models are used when the parameter estimates of the selected studies are homogeneous, while random models are used when evidence of heterogeneity is found), the choice of the model should depend on the interferences one wants to make. That is, if one wants to make interferences about the selected studies then a fixed model approach is appropriate, while as one wants to make interferences beyond the selected studies then one should use a random model approach (Hedges and Vevea 1998).

\section{Results}

Table 2 displays the results of the meta-analyses. Homogeneity tests were significant for all meta-analyses indicating substantial heterogeneity across studies, and therefore moderators (mean age and mean IQ) were analyzed using the random effects model.
It was found that youth with ASD had higher anxiety levels compared to typically developing children. This finding was consistent across models (fixed and random) and respondents (parent and child report), see Table 2. Mean age was not found to moderate the difference in anxiety levels between children with ASD and typically developing youth $(\beta=0.11, Z=0.95, p=.340)$, however, mean IQ was found to be significant $(\beta=0.33, Z=4.48$, $p<.001)$. This result indicates that the difference in anxiety levels between youth with ASD and typically developing youth is related to IQ; that is, as the mean level of IQ of youth with ASD increases, the difference between ASD and typically developing youth in anxiety levels increases as well.

Youth with ASD tend to have higher anxiety levels compared to clinically referred youth, but the results are not consistent, see Table 2. For the fixed effect model a (small) significant difference between ASD and clinically referred youth was found, while for the random effect model this difference was not significant. In addition, child report yielded a significant difference for both the fixed and random effect model, while for parent report the fixed effect model only (and not the random model) indicated a significant difference. Mean age was found to be a significant moderator $(\beta=0.33, \quad Z=2.34$, $p=.019)$, however mean IQ was not $(\beta=0.30, Z=1.35$, $p=.178$ ). It was found that as age increased, so did the difference in anxiety levels between ASD and clinically referred youth.

Table 3 displays the results of the meta-analyses comparing the anxiety levels of children with ASD to various clinical comparison groups. It was found that children with ASD have higher anxiety levels compared to youth with externalizing or developmental problems, but not compared to youth with internalizing problems. Furthermore, the results for the comparison between ASD and youth with internalizing problems are inconsistent across models. That is, no significant difference between youth with ASD and youth with internalizing problems was found for the random effect model, while youth with internalizing problems had significantly higher anxiety levels (small effect) than youth with ASD when using the fixed effect model.

\section{Discussion}

This study compared the anxiety levels of youth with ASD to typically developing children and clinically referred children using a meta-analytical approach. Most important findings are that: (1) anxiety levels of youth with ASD are much higher compared to typically developing children (large effect size difference); (2) anxiety levels of children 
with ASD seem elevated compared to clinically referred children in general (small effect size difference); (3) the type of comparison group seems to matter in the direction that anxiety levels in youth with ASD were found to be higher compared to youth with externalizing or developmental problems, but compared to children with internalizing problems results were inconsistent for the fixed and random model; (4) as IQ increases, so does the difference in anxiety levels between ASD and typically developing children, and (5) as age increases, so does the difference in anxiety levels between ASD and clinically referred children.

The finding that youth with ASD have higher anxiety levels compared to typically developing children is hardly surprising. However, youth with ASD also tend to have higher anxiety levels compared to clinically referred youth (with a small to medium effect size). Therefore it seems that children with ASD are more prone for anxiety problems than other-typically developing and clinically referredchildren. Different explanations for these findings have been suggested by various authors (see Bellini 2006, who propose a model for the development of social anxiety in ASD; Wood and Gadow 2010, who propose a model in which ASD and anxiety exacerbate each other; van Steensel et al. (2014) who do not propose an explicit model for the development of anxiety in ASD but do consider other family factors (e.g., parental stress/anxiety, parenting behaviors), next to genetic and ASD-related factors). Taken together, it is thought that children with ASD have a neurobiological predisposition which cause ASD-related difficulties which, in combination with environmental factors (bullying, parenting, etc.), may lead to anxiety. However, more (longitudinal) research, examining both ASD-specific (e.g., theory of mind deficits, severity of ASD, executive functioning problems, social skills deficits) as well as more general factors (e.g., stressful lifeevents, parental anxiety, parental rearing behaviors) is needed to understand this complex co-occurrence of anxiety and ASD.

It was found in this meta-analysis that the difference in anxiety levels between children with ASD and typically developing children increased when children with ASD had higher IQs, and that the difference in anxiety levels between children with ASD and clinically referred children increased with age. These results are consistent with other studies demonstrating that anxiety in ASD is related to an older age and higher levels of cognitive functioning (e.g., Eussen et al. 2013; Gadow et al. 2005; Mayes et al. 2011). It may be that older children with ASD, and children with ASD who have higher levels of cognitive functioning, are more aware of their difficulties. In combination with possibly higher demands of their surroundings to adapt or to 'fit in', this may lead to more stress and higher levels of anxiety. Therefore, especially high-functioning adolescents with ASD may be at risk for developing anxiety disorders and it may be worth to carefully follow and monitor children with ASD transcending to adolescence.
Table 2 Results of the metaanalyses comparing the anxiety levels of youth with ASD to typical developing and clinically referred youth

\begin{tabular}{|c|c|c|c|c|c|c|c|}
\hline & $k$ & Model & $d$ & SE & $Z$ & $Q$ & $p$ \\
\hline \multicolumn{8}{|c|}{ ASD vs. typically developing youth } \\
\hline \multirow[t]{3}{*}{ Parent + child } & 64 & Fixed & 0.78 & .0001 & 6158.87 & & $<.001$ \\
\hline & & Random & 0.97 & .0742 & 13.13 & & $<.001$ \\
\hline & & Homogeneity test & & & & $5,664,859.99$ & $<.001$ \\
\hline \multirow[t]{3}{*}{ Parent } & 53 & Fixed & 0.78 & .0001 & 5998.65 & & $<.001$ \\
\hline & & Random & 1.21 & .1051 & 11.54 & & $<.001$ \\
\hline & & Homogeneity test & & & & $6,394,385.12$ & $<.001$ \\
\hline \multirow[t]{3}{*}{ Child } & 33 & Fixed & 0.91 & .0005 & 1850.99 & & $<.001$ \\
\hline & & Random & 0.65 & .0669 & 9.72 & & $<.001$ \\
\hline & & Homogeneity test & & & & $297,566.26$ & $<.001$ \\
\hline \multicolumn{8}{|c|}{ ASD vs. clinically referred youth } \\
\hline \multirow[t]{3}{*}{ Parent + child } & 35 & Fixed & 0.23 & .0004 & 590.17 & & $<.001$ \\
\hline & & Random & 0.12 & .0696 & 1.76 & & .077 \\
\hline & & Homogeneity test & & & & $942,390.70$ & $<.001$ \\
\hline \multirow[t]{3}{*}{ Parent } & 29 & Fixed & 0.26 & .0004 & 645.74 & & $<.001$ \\
\hline & & Random & 0.13 & .0807 & 1.62 & & .105 \\
\hline & & Homogeneity test & & & & $982,528.51$ & $<.001$ \\
\hline \multirow[t]{3}{*}{ Child } & 12 & Fixed & 0.11 & .0009 & 127.77 & & $<.001$ \\
\hline & & Random & 0.22 & .0675 & 3.25 & & .001 \\
\hline & & Homogeneity test & & & & $49,966.92$ & $<.001$ \\
\hline
\end{tabular}


Table 3 Results of the metaanalyses comparing the anxiety levels of youth with ASD to various clinical groups (based on aggregated parent + child report)

\begin{tabular}{|c|c|c|c|c|c|c|c|}
\hline ASD vs. & $k$ & Model & $d$ & SE & $Z$ & $Q$ & $p$ \\
\hline \multirow[t]{3}{*}{ Internalizing } & 12 & Fixed & -0.21 & .0009 & -246.90 & & $<.001$ \\
\hline & & Random & -0.45 & .3302 & -1.36 & & .175 \\
\hline & & Homogeneity test & & & & $1,310,505.96$ & $<.001$ \\
\hline \multirow[t]{3}{*}{ Externalizing } & 9 & Fixed & 0.20 & .0015 & 136.78 & & $<.001$ \\
\hline & & Random & 0.38 & .1311 & 2.89 & & .003 \\
\hline & & Homogeneity test & & & & $54,716.59$ & $<.001$ \\
\hline \multirow[t]{3}{*}{ Developmental } & 14 & Fixed & 0.43 & .0006 & 769.95 & & $<.001$ \\
\hline & & Random & 0.32 & .0690 & 4.65 & & $<.001$ \\
\hline & & Homogeneity test & & & & $109,196.76$ & $<.001$ \\
\hline
\end{tabular}

\section{Limitations}

First, significant heterogeneity across studies was found for all meta-analyses. An attempt was made to explain this heterogeneity by including moderators (IQ and age) and by subdividing the clinical comparison groups. Although these variables explained some of the heterogeneity, it still remained significant in all models. Other methodological factors may account for this heterogeneity; e.g., the use of different ASD-samples (e.g., community-based vs. clinically referred), or the different instruments that were used across studies (see Table 1) to assess anxiety (e.g., anxiety specific questionnaire vs. general behavioral questionnaire). In addition, the type of informant (parent vs. child-report) may have played a role. That is, the use of parent-report seems to lead to larger differences in anxiety levels between children with ASD and their comparison group than the use of child reports (see Table 1).

Second, most studies used questionnaires that were not specific for ASD (Table 1). Although this was needed to make a valid comparison to the typically developing children or to the clinically referred youth, it may also have a risk for potential measurement bias. That is, symptoms of ASD and anxiety are not always easy to disentangle and when parents need to fill in a questionnaire there is no way of knowing whether a particular symptom (e.g., 'is afraid to be among unfamiliar people') needs to be seen as related to ASD or to anxiety. Due to this mix-up of symptoms, children with ASD may automatically score higher on those questionnaires and cutoffs of traditional anxiety questionnaires may need to be adjusted (e.g., van Steensel et al. 2013). In addition, it is questionable whether the construct of anxiety is similar in youth with ASD. That is, the study of White et al. (2015a) examined the structure of the Multidimensional Anxiety Scale for Children (MASC) with and without ASD and found that while the same factors were found, the levels and relations among factors were found to be different. On the other hand, some traditional measures seem to work quite well for capturing anxiety in (high- functioning) youth with ASD in terms of clinical relevance, psychometric properties (validity, reliability) and sensitivity to change (see Lecavalier et al. 2014).

Third, this meta-analysis demonstrated that the type of comparison group is a relevant factor to consider, however, the number of studies comparing children with ASD to a specific clinical comparison group (e.g., youth with externalizing problems, youth with internalizing problems, etc.) was rather small and too small to conduct analyses separately for child and parent report. In addition, results regarding the comparison between children with ASD and children with internalizing problems were inconsistent across the fixed and random models. That is, while the fixed effects model yielded a (small) significant difference in the direction that youth with internalizing problems had higher anxiety levels, this difference was not found in the random model (indicating similar anxiety levels). Therefore, more research comparing groups of children with ASD to specific clinical samples is needed to draw more definite conclusions.

Finally, a moderating influence of age and IQ was found in this meta-analysis, however, most studies used ASD groups with normal levels of cognitive functioning and with mean ages ranging between 8 and 14 (Table 1). Therefore, future research should focus on both very young children with ASD ( $<6$ years) as well as adolescents ( $>15$ years), and children with lower functioning IQs $(<70)$, as they seem to be somewhat under-represented to date.

\section{Implications}

Given the findings of this study-which demonstrate elevated anxiety levels in youth with ASD-it seems important to develop appropriate screening instruments for anxiety in ASD, in particular as treatment options (e.g., cognitive behavioral therapy) are becoming available and are found to be effective to decrease anxiety in youth with ASD (see meta-analysis of Sukhodolsky et al. 2013). Nowadays, instruments to measure anxiety in ASD are not specifically 
developed for children with ASD and although the psychometric properties of these instruments seem acceptable for youth with ASD (see review of Lecavalier et al. 2014), for most of these instruments appropriate cutoffs for ASD are lacking. In addition, it is a challenge to distinguish anxiety from ASD. Noteworthy is the study of Ozsivadjian et al. (2012) which examined anxiety triggers and the impact of anxiety symptoms in children with ASD in a focus group. They found evidence for both general anxiety triggers and symptoms (e.g., social worries, specific phobias, avoidance) as well as some ASD-specific triggers and symptoms (e.g., the intensity and pervasiveness of anxiety, sensory sensitivities, social difficulties). Furthermore, the study highlights the impact of anxiety for the daily functioning - not only for the children themselves, but also for the family. It was even noted that the anxiety might have a greater impact on the family life than the ASD, resulting in a further decrease in quality of life (Ozsivadjian et al. 2012). In accordance, the study of van Steensel et al. (2012) demonstrated that anxiety problems in youth with ASD have a negative impact on quality of life, over and above the ASD symptoms. Taken together, the high levels of anxiety in youth with ASD found in this meta-analysis-and the impact of anxiety on the daily functioning of individuals with ASD as demonstrated by previous studies-stresses the importance to gain more insight in the nature and development of anxiety in youth with ASD, as well as the importance of developing appropriate measures and (prevention) treatments.

\section{Compliance with Ethical Standards}

Conflict of Interest The authors declare that they have no conflict of interest.

Ethical Approval This article does not contain any studies with human participants performed by any of the authors.

Open Access This article is distributed under the terms of the Creative Commons Attribution 4.0 International License (http:// creativecommons.org/licenses/by/4.0/), which permits unrestricted use, distribution, and reproduction in any medium, provided you give appropriate credit to the original author(s) and the source, provide a link to the Creative Commons license, and indicate if changes were made.

\section{References}

Articles marked by an asterisk are included in the meta-analyses

American Psychiatric Association. (2013). Diagnostic and statistical manual of mental disorders, (5th edn.). Arlington, VA: American Psychiatric Publishing.

*Bauminger, N., Solomon, M., \& Rogers, S. J. (2010). Externalizing and internalizing behaviors in ASD. Autism Research, 3, $101-112$.
*Bellini, S. (2004). Social skill deficits and anxiety in high-functioning adolescents with autism spectrum disorders. Focus on Autism and Other Developmental Disabilities, 19, 78-86.

Bellini, S. (2006). The development of social anxiety in adolescents with autism spectrum disorders. Focus on Autism and Other Developmental Disabilities, 21, 138-145.

*Bitsika, V., \& Sharpley, C. F. (2015). Variation in the profile of anxiety disorders in boys with an ASD according to method and source of assessment. Journal of Autism and Developmental Disorders, 45, 1825-1835.

*Blakeley-Smith, A., Reaven, J., Ridge, K., \& Hepburn, S. (2012). Parent-child agreement of anxiety symptoms in youth with autism spectrum disorders. Research in Autism Spectrum Disorders, 6, 707-716.

*Boulter, C., Freeston, M., South, M., \& Rodgers, J. (2014). Intolerance of uncertainty as a framework for understanding anxiety in children and adolescents with autism spectrum disorders. Journal of Autism and Developmental Disorders, 44, 1391-1402.

*Bradley, E. A., Summers, J. A., Wood, H. L., \& Bryson, S. E. (2004). Comparing rates of psychiatric and behavior disorders in adolescents and young adults with severe intellectual disability with and without autism. Journal of Autism and Developmental Disorders, 34, 151-161.

*Brereton, A. V., Tonge, B. J., \& Einfeld, S. L. (2006). Psychopathology in children and adolescents with autism compared to young people with intellectual disability. Journal of Autism and Developmental Disorders, 36, 863-870.

Brown-Jacobsen, A. M., Wallace, D. P., \& Whiteside, S. P. H. (2011). Multimethod, multi-informant agreement, and positive predictive value in the identification of child anxiety disorders using the SCAS and ADIS-C. Assessment, 18, 382-392.

de Bruin, E. I., Ferdinand, R. F., Meester, S., de Nijs, P. F., \& Verheij, F. (2007). High rates of psychiatric co-morbidity in PDD-NOS. Journal of Autism and Developmental Disorders, 37, 877-886.

*Burnette, C. P., Mundy, P. C., Meyer, J. A., Sutton, S. K., Vaughan, A. E., \& Charak, D. (2005). Weak central coherence and its relations to theory of mind and anxiety in autism. Journal of Autism and Developmental Disorders, 35, 63-73.

*Chamberlain, P. D., Rodgers, J., Crowley, M. J., White, S. E., Freeston, M. H., \& South, M. (2013). A potentiated startle study of uncertainty and contextual anxiety in adolescents diagnosed with autism spectrum disorder. Molecular Autism, 4, 31.

*Cholemkery, H., Kitzerow, J., Rohrmann, S., \& Freitag, C. M. (2014a). Validity of the social responsiveness scale to differentiate between autism spectrum disorders and disruptive behaviour disorders. European Child \& Adolescent Psychiatry, 23, 81-93.

*Cholemkery, H., Mojica, L., Rohrmann, S., Gensthaler, A., \& Freitag, C. M. (2014b). Can autism spectrum disorders and social anxiety disorders be differentiated by the social responsiveness scale in children and adolescents? Journal of Autism and Developmental Disorders, 44, 1168-1182.

*Clawson, A., Clayson, P. E., Worsham, W., Johnston, O., South, M., \& Larson, M. J. (2014). How about watching others? Observation of error-related feedback by others in autism spectrum disorders. International Journal of Psychophysiology, 92, 26-34.

Comer, J. S., \& Kendall, P. C. (2004). A symptom-level examination of parent-child agreement in the diagnosis of anxious youths. Journal of the American Academy of Child \& Adolescent Psychiatry, 43, 878-886.

Costello, E. J., Egger, H. L., \& Angold, A. (2005). The developmental epidemiology of anxiety disorders: Phenomenology, prevalence, and comorbidity. Child and Adolescent Psychiatric Clinics of North America, 14, 631-648.

*Davis, III, T. E., Fodstad, J. C., Jenkins, W. S., Hess, J. A., Moree, B. N., Dempsey, T., \& Matson, J. L. (2010). Anxiety and avoidance 
in infants and toddlers with autism spectrum disorders: Evidence for differing symptom severity and presentation. Research in Autism Spectrum Disorders, 4, 305-313.

*Dewrang, P., \& Sandberg, A. D. (2011). Repetitive behaviour and obsessive-compulsive features in Asperger syndrome: Parental and self-reports. Research in Autism Spectrum Disorders, 5, 1176-1186.

Eussen, M. L., Van Gool, A. R., Verheij, F., De Nijs, P. F., Verhulst, F. C., \& Greaves-Lord, K. (2013). The association of quality of social relations, symptom severity and intelligence with anxiety in children with autism spectrum disorders. Autism : The International Journal of Research and Practice, 17, 723-735.

*Farrugia, S., \& Hudson, J. (2006). Anxiety in adolescents with Asperger syndrome: Negative thoughts, behavioral problems, and life interference. Focus on Autism and Other Developmental Disabilities, 21, 25-35.

*Gadow, K. D., DeVincent, C. J., Pomeroy, J., \& Azizian, A. (2004). Psychiatric symptoms in preschool children with PDD and clinic and comparison samples. Journal of Autism and Developmental Disorders, 34, 379-393.

*Gadow, K. D., Devincent, C. J., Pomeroy, J., \& Azizian, A. (2005). Comparison of DSM IV symptoms in elementary school-age children with PDD versus clinic and community samples. Autism: The International Journal of Research and Practice, 9, 392-415.

*Gadow, K. D., DeVincent, C. J., \& Schneider, J. (2009). Comparative study of children with ADHD only, autism spectrum disorder + ADHD, and chronic multiple tic disorder+ ADHD. Journal of Attention Disorders, 12, 474-485.

*Gillott, A., Furniss, F., \& Walter, A. (2001). Anxiety in highfunctioning children with autism. Autism: The International Journal of Research and Practice, 5, 277-286.

*Goldin, R. L., Matson, J. L., Konst, M. J., \& Adams, H. L. (2014). A comparison of children and adolescents with ASD, atypical development, and typical development on the behavioral assessment system for children, (BASC-2). Research in Autism Spectrum Disorders, 8, 951-957.

*von Gontard, A., Pirrung, M., Niemczyk, J., \& Equit, M. (2015). Incontinence in children with autism spectrum disorder. Journal of Pediatric Urology, 11, 264.e1-264.e7.

Green, J., Gilchrist, A., Burton, D., \& Cox, A. (2000). Social and psychiatric functioning in adolescents with Asperger syndrome compared with conduct disorder. Journal of Autism and Developmental Disorders, 30, 279-293.

*Green, S. A., Rudie, J. D., Colich, N. L., Wood, J. J., Shirinyan, D., Hernandez, L., Tottenham, N., Dapretto, M., \& Bookheimer, S. Y. (2013). Overreactive brain responses to sensory stimuli in youth with autism spectrum disorders. Journal of the American Academy of Child \& Adolescent Psychiatry, 52, $1158-1172$.

*Greenaway, R., \& Howlin, P. (2010). Dysfunctional attitudes and perfectionism and their relationship to anxious and depressive symptoms in boys with autism spectrum disorders. Journal of Autism and Developmental Disorders, 40, 1179-1187.

*Griffith, G. M., Hastings, R. P., Nash, S., \& Hill, C. (2010). Using matched groups to explore child behavior problems and maternal well-being in children with Down syndrome and autism. Journal of Autism and Developmental Disorders, 40, 610-619.

Grills, A. E., \& Ollendick, T. H. (2003). Multiple informant agreement and the anxiety disorders interview schedule for parents and children. Journal of the American Academy of Child \& Adolescent Psychiatry, 42, 30-40.

*Guttmann-Steinmetz, S., Gadow, K. D., DeVincent, C. J., \& Crowell, J. (2010). Anxiety symptoms in boys with autism spectrum disorder, attention-deficit hyperactivity disorder, or chronic multiple tic disorder and community controls. Journal of Autism and Developmental Disorders, 40, 1006-1016.
*Guy, L., Souders, M., Bradstreet, L., Delussey, C., \& Herrington, J. D. (2014). Brief report: Emotion regulation and respiratory sinus arrhythmia in autism spectrum disorder. Journal of Autism and Developmental Disorders, 44, 2614-2620.

*Hallett, V., Ronald, A., Colvert, E., Ames, C., Woodhouse, E., Lietz, S., Garnett, T., Gillan, N., Rijsdijk, F., Scahill, L., Bolton, P., \& Happé, F. (2013). Exploring anxiety symptoms in a large-scale twin study of children with autism spectrum disorders, their cotwins and controls. Journal of Child Psychology and Psychiatry, $54,1176-1185$.

*Hebron, J., \& Humphrey, N. (2014). Mental health difficulties among young people on the autistic spectrum in mainstream secondary schools: A comparative study. Journal of Research in Special Educational Needs, 14, 22-32.

Hedges, L. V., \& Vevea, J. L. (1998). Fixed- and random-effects models in meta-analysis. Psychological Methods, 3, 486-504.

*Hollocks, M. J., Howlin, P., Papadopoulos, A. S., Khondoker, M., \& Simonoff, E. (2014). Differences in HPA-axis and heart rate responsiveness to psychosocial stress in children with autism spectrum disorders with and without co-morbid anxiety. Psychoneuroendocrinology, 46, 32-45.

*Hollocks, M. J., Ozsivadjian, A., Matthews, C. E., Howlin, P., \& Simonoff, E. (2013). The relationship between attentional bias and anxiety in children and adolescents with autism spectrum disorders. Autism Research, 6, 237-247.

*Jarrold, W., Mundy, P., Gwwaltney, M., Bailenson, J., Hatt, N., McIntyre, N., Kwanguk, K., Solomon, M., Novotny, S., \& Swain, L. (2013). Social attention in a virtual public speaking task in higher functioning children with autism. Autism Research, 6, 393-410.

Joshi, G., Petty, C., Wozniak, J., Henin, A., Fried, R., Galdo, M., Kotarski, M., Walls, S., \& Biederman, J. (2010). The heavy burden of psychiatric comorbidity in youth with autism spectrum disorders: A large comparative study of a psychiatrically referred population. Journal of Autism and Developmental Disorders, 40, 1361-1370.

*Kim, J. A., Szatmari, P., Bryson, S., Streiner, D. L., \& Wilson, F. J. (2000). The prevalence of anxiety and mood problems among children with autism and Asperger syndrome. Autism : The International Journal of Research and Practice, 4, 117-132.

*Kim, K., Rosenthal, M. Z., Gwaltney, M., Jarrold, W., Hatt, N., McIntyre, N., Solomon, M., \& Mundy, P. (2014). A virtual joystick study of emotional responses and social motivation in children with autism spectrum disorder. Journal of Autism and Developmental Disorders, 45, 3891-3899.

*Kline, R. B., Lachar, D., \& Gdowski, C. L. (1987). A personality inventory for children profile typology of children and adolescents: II. Classification rules and specific behavior correlates. Journal of Clinical Child Psychology, 16, 225-234.

*Kuusikko, S., Pollock-Wurman, R., Jussila, K., Carter, A. S., Mattila, M. L., \& Ebeling, H., et al. (2008). Social anxiety in highfunctioning children and adolescents with autism and Asperger syndrome. Journal of Autism and Developmental Disorders, 38, 1697-1709.

*Lawson, R. A., Papadakis, A. A., Higginson, C. I., Barnett, J. E., Willis, M. C., Strang, J. F., Wallace, G. L., \& Kenworthy, L. (2015). Everyday executive function impairments predict comorbide psychopathology in autism spectrum and attention deficit hyperactivity disorders. Neuropsychology, 29, 445-453.

Lecavalier, L., Wood, J. J., Halladay, A. K., Jones, N. E., Aman, M. G., Cook, E. H., Handen, B. L., King, B. H., Pearson, D. A., Hallett, V., Sullivan, K. A., Grondhuis, S., Bishop, S. L., Horrigan, J. P., Dawson, G., \& Scahill, L. (2014). Measuring anxiety as a treatment endpoint in youth with autism spectrum disorder. Journal of Autism and Developmental Disorders, 44, $1128-1143$. 
Leyfer, O. T., Folstein, S. E., Bacalman, S., Davis, N. O., Dinh, E., Morgan, J., Tager-Flusberg, H., \& Lainhart, J. E. (2006). Comorbid psychiatric disorders in children with autism: Interview development and rates of disorders. Journal of Autism and Developmental Disorders, 36, 849-861.

*Lopata, C., Toomey, J. A., Fox, J. D., Volker, M. A., Chow, S. Y., Thomeer, M. L., Lee, G. K., Rodgers, J. D., McDonald, C. A., \& Smerbeck, A. M. (2010). Anxiety and depression in children with HFASDs: Symptom levels and source differences. Journal of Abnormal Child Psychology, 38, 765-776.

MacNeil, B. M., Lopes, V. A., \& Minnes, P. M. (2009). Anxiety in children and adolescents with autism spectrum disorders. Research in Autism Spectrum Disorders, 3, 1-21.

*Mahan, S., \& Matson, J. L. (2011). Children and adolescents with autism spectrum disorders compared to typically developing controls on the behavioral assessment system for children, (BASC-2). Research in Autism Spectrum Disorders, 5, 119-125.

*Matson, J. L., \& Love, S. R. (1990). A comparison of parent-reported fear for autistic and nonhandicapped age-matched children and youth. Journal of Intellectual and Developmental Disability, 16, 349-357.

*May, T., Cornish, K., Conduit, R., Rajaratnam, S. M. W., \& Rinehart, N. J. (2015c). Sleep in high-functioning children with autism: Longitudinal developmental change and associations with behavior problems. Behavioral Sleep Medicine, 13, 2-18.

*May, T., Cornish, K., \& Rinehart, N. (2014). Does gender matter? A one year follow-up of autistic, attention and anxiety symptoms in high-functioning children with autism spectrum disorder. Journal of Autism and Developmental Disorders, 44, 1077-1086.

*May, T., Cornish, K., \& Rinehart, N.J. (2015a). Parent-child agreement using the spence children's anxiety scale and a thermometer in children with autism spectrum disorder. Autism Research and Treatment, 2015, Article ID 315495, 9 pages. doi:10.1155/2015/ 315495 .

*May, T., Cornish, K., \& Rinehart, N. J. (2015b). Mechanisms of anxiety related attentional biases in children with autism spectrum disorder. Journal of Autism and Developmental Disorders, 45, 3339-3350.

Mayes, S. D., Calhoun, S. L., Murray, M. J., \& Zahid, J. (2011). Variables associated with anxiety and depression in children with autism. Journal of Developmental and Physical Disabilities, 23, 325-337.

*Mazefsky, C. A., Anderson, R., Conner, C. M., \& Minshew, N. (2011). Child behavior checklist scores for school-aged children with autism: Preliminary evidence of patterns suggesting the need for referral. Journal of Psychopathology and Behavioral Assessment, 33, 31-37.

*Mazefsky, C. A., Borue, X., Day, T. N., \& Minshew, N. J. (2014). Emotion regulation patterns in adolescents with high-functioning autism spectrum disorder: Comparison to typically developing adolescents and association with psychiatric symptoms. Autism Research, 7, 344-354.

*Mazzone, L., Postorino, V., De Peppo, L., Fatta, L., Lucarelli, V., Reale, L., Giovagnoli, G., \& Vicari, S. (2013). Mood symptoms in children and adolescents with autism spectrum disorders. Research in Developmental Disabilities, 34, 3699-3708.

*Melfsen, S., Walitza, S., \& Warnke, A. (2006). The extent of social anxiety in combination with mental disorders. European Child \& Adolescent Psychiatry, 15, 111-117.

*Meyer, J. A., Mundy, P. C., Van Hecke, A. V., \& Durocher, J. S. (2006). Social attribution processes and comorbid psychiatric symptoms in children with Asperger syndrome. Autism: The International Journal of Research and Practice, 10, 383-402.

*Mikita, N., Hollocks, M. J., Papadopoulus, A. S., Aslani, A., Harrison, S., Leibenluft, E., Simonoff, E., \& Stringaris, A. (2015). Irritability in boys with autism spectrum disorders: An investigation of physiological reactivity. Journal of Child Psychology and Psychiatry, 56, 1118-1126.

*Miller, M., Bales, K. L., Taylor, S. L., Yoon, J., Hostetler, C. M., Carter, C. S., \& Solomon, M. (2013). Oxytocin and vasopressin in children and adolescents with autism spectrum disorders: Sex differences and associations with symptoms. Autism Research, 6, 91-102.

*Muratori, F., Narzisi, A., Tancredi, R., Cosenza, A., Calugi, S., Saviozzi, I., Santocchi, E., \& Calderoni, S. (2011). The CBCL $1.5-5$ and the identification of preschoolers with autism in Italy. Epidemiology and Psychiatric Sciences, 20, 329-338.

*Ooi, Y. P., Rescorla, L., Ang, R. P., Woo, B., \& Fung, D. S. (2011). Identification of autism spectrum disorders using the child behavior checklist in Singapore. Journal of Autism and Developmental Disorders, 41, 1147-1156.

*Oswald, T. M., Winter-Messiers, M. A., Gibson, B., Schmidt, A. M., Herr, C. M., \& Solomon, M. (2016). Sex differences in internalizing problems during adolescence in autism spectrum disorder. Journal of Autism and Developmental Disorders, 46, 624-636.

Ozsivadjian, A., Knott, F., \& Magiati, I. (2012). Parent and child perspectives on the nature of anxiety in children and young people with autism spectrum disorders: A focus group study. Autism: The International Journal of Research and Practice, 16, 107-121.

*Park, J. H., Kim, Y. S., Koh, Y. J., Song, J., \& Leventhal, B. L. (2014). A contrast of comorbid condition and adaptive function between children with autism spectrum disorder from clinical and non-clinical populations. Research in Autism Spectrum Disorders, 8, 1471-1481.

*Park, S., Park, M. H., Kim, H. J., \& Yoo, H. J. (2013). Anxiety and depression symptoms in children with Asperger syndrome compared with attention-deficit/hyperactivity disorder and depressive disorder. Journal of Child and Family Studies, 22, $559-568$

*Piper, B. J., Gray, H. M., Raber, J., \& Birkett, M. A. (2014). Reliability and validity of brief problem monitor, an abbreviated for of the child behavior checklist. Psychiatry and Clinical Neurosciences, 68, 759-767.

*Predescu, E., Şopros, R., Dobrean, A., \& Micluția, I. (2013). The discriminative power of the CBCL $1.5-5$ between autism spectrum disorders and other psychiatric disorders. Journal of Cognitive \& Behavioral Psychotherapies, 13, 75-87.

*Pugliese, C. E., White, B. A., White, S. W., \& Ollendick, T. H. (2013). Social anxiety predicts aggression in children with ASD: Clinical comparisons with socially anxious and oppositional youth. Journal of Autism and Developmental Disorders, 43, 1205-1213.

*Rescorla, L., Kim, Y. A., \& Oh, K. J. (2014). Screening for ASD with the Korean CBCL/ 1.5-5. Journal of Autism and Developmental Disorders, 45, 4039-4050.

*Richdale, A. L., \& Baglin, C. L. (2015). Self-report and caregiverreport of sleep and psychopathology in children with highfunctioning autism spectrum disorder: A pilot study. Developmental Neurorehabilitation, 18, 272-279.

*Richdale, A. L., Baker, E., Short, M., \& Gradisar, M. (2014). The role of insomnia, pre sleep arousal and psychopathology symptoms in daytime impairment in adolescents with highfunctioning autism spectrum disorder. Sleep Medicine, 15, 1082-1088.

*Rieske, R. D., Matson, J. L., May, A. C., \& Kozlowski, A. M. (2012). Anxiety in children with high-functioning autism spectrum disorders: Significant differences and the moderating effects of social impairments. Journal of Developmental and Physical Disabilities, 24, 167-180. 
*van Rijn, S., Stockmann, L., Borghgraef, M., Bruining, H., van Ravenswaaij-Arts, C., Govaerts, L., Hansson, K., \& Swaab, H. (2014). The social behavioral phenotype in boys and girls with an extra X chromosome (Klinefelter syndrome and trisomy $\mathrm{X}$ ): A comparison with autism spectrum disorder. Journal of Autism and Developmental Disorders, 44, 310-320.

*Rodgers, J., Riby, D. M., Janes, E., Connolly, B., \& McConachie, H. (2012). Anxiety and repetitive behaviours in autism spectrum disorders and Williams syndrome: A cross syndrome comparison. Journal of Autism and Developmental Disorders, 42, 175-180.

*Russell, E., \& Sofronoff, K. (2005). Anxiety and social worries in children with Asperger syndrome. Australian and New Zealand Journal of Psychiatry, 39, 633-638.

*Samson, A. C., Wells, W. M., Phillips, J. M., Hardan, A. Y., \& Gross, J. J. (2015). Emotion regulation in autism spectrum disorder: Evidence from parent interviews and children's daily diaries. Journal of Child Psychology and Psychiatry, 56, 903-913.

*Schroeder, J., Weiss, J., \& Bebko, J. (2011). CBCL Profiles of children and adolescents with Asperger syndrome: A review and pilot study. Journal on Developmental Disabilities, 17, 26-37.

*Schwenk, C., \& Freitag, C. M. (2014). Differentiation between attention-deficit/hyperactivity disorder and autism spectrum disorder by the social communication questionnaire. ADHD Attention Deficit and Hyperactivity Disorders, 6, 221-229.

*Sharma, S., Woolfson, L. M., \& Hunter, S. C. (2014). Maladaptive cognitive appraisals in children with high-functioning autism: Associations with fear, anxiety and theory of mind. Autism: the international journal of research and practice, 18, 244-254.

*Simon, D. M., \& Corbett, B. A. (2013). Examining associations between anxiety and cortisol in high functioning male children with autism. Journal of Neurodevelopmental Disorders, 5, 32 doi:10.1186/1866-1955-5-32.

Simonoff, E., Pickles, A., Charman, T., Chandler, S., Loucas, T., \& Baird, G. (2008). Psychiatric disorders in children with autism spectrum disorders: Prevalence, comorbidity, and associated factors in a population-derived sample. Journal of the American Academy of Child \& Adolescent Psychiatry, 47, 921-929.

*Skokauskas, N., \& Gallagher, L. (2012). Mental health aspects of autistic spectrum disorders in children. Journal of Intellectual Disability Research, 56, 248-257.

*Solomon, M., Miller, M., Taylor, S. L., Hinshaw, S. P., \& Carter, C. S. (2012). Autism symptoms and internalizing psychopathology in girls and boys with autism spectrum disorders. Journal of Autism and Developmental Disorders, 42, 48-59.

Van Steensel, F. J. A., Bögels, S. M., \& de Bruin, E. I. (2013). Psychiatric comorbidity in children with autism spectrum disorders: A comparison with children with ADHD. Journal of Child and Family Studies, 22, 368-376.

*van Steensel, F. J. A., Bögels, S. M., \& Dirksen, C. D. (2012). Anxiety and quality of life: Clinically anxious children with and without autism spectrum disorders compared. Journal of Clinical Child \& Adolescent Psychology, 41, 731-738.

van Steensel, F. J. A., Bögels, S. M., Magiati, I., \& Perrin, S. (2014). Anxiety in individuals with ASD: Prevalence, phenomenology, etiology, assessment, and interventions. In V. B. Patel, V. R. Preedy, C. R. Martin (Eds). Comprehensive Guide to Autism (pp. 601-623). New York, NY: Springer.

van Steensel, F. J. A., Bögels, S. M., \& Perrin, S. (2011). Anxiety disorders in children and adolescents with autistic spectrum disorders: A meta-analysis. Clinical Child and Family Psychology Review, 14, 302-317.

van Steensel, F. J. A., Deutschman, A. A. C. G., \& Bögels, S. M. (2013). Examining the screen for child anxiety-related and emotional disorder-71 as an assessment tool in children with high-functioning autism spectrum disorders. Autism : The International Journal of Research and Practice, 17, 681-692.

*Stein, L.I., Lane, C.J., Williams, M.E., Dawson, M.E., Polido, J.C., \& Cermak, S.A. (2014). Physiological and behavioral stress and anxiety in children with autism spectrum disorders during routine oral care. BioMed Research International, 2014, Article ID 694876, 10 pages, 2014. doi:10.1155/2014/694876.

*Sterling, L., Munson, F., Estes, A., Murias, M., Webb, S. J., King, B., \& Dawson, G. (2013). Fear-potentiated startle response is unrelated to social or emotional functioning in adolescents with autism spectrum disorders. Autism Research, 6, 320-331.

*Stoppelbein, L., Biasini, F., Pennick, M., \& Greening, L. (2016). Predicting internalizing and externalizing symptoms among children diagnosed with an autism spectrum disorder: The role of routines. Journal of Child and Family Studies, 25, 251-261.

Sukhodolsky, D. G., Bloch, M. H., Panza, K. E., \& Reichow, B. (2013). Cognitive behavioral therapy for anxiety in children with high-functioning autism: A meta-analysis. Pediatrics, 132, 1341-1350.

*Swartz, J. R., Wiggins, J. L., Carrasco, M., Lord, C., \& Monk, C. S. (2013). Amygdala habituation and prefrontal functional connectivity in youth with autism spectrum disorders. Journal of the American Academy of Child \& Adolescent Psychiatry, 52, 84-93.

*Thede, L. L., \& Coolidge, F. L. (2007). Psychological and neurobehavioral comparisons of children with Asperger's disorder versus high-functioning autism. Journal of Autism and Developmental Disorders, 37, 847-854.

*Thurman, A. J., McDuffie, A., Hagerman, R., \& Abbeduto, L. (2014). Psychiatric symptoms in boys with fragile X syndrome: A comparison with nonsyndromic autism spectrum disorder. Research in Developmental Disabilities, 35, 1072-1086.

*Tonge, B. J., \& Einfeld, S. L. (2003). Psychopathology and intellectual disability: The Australian child to adult longitudinal study. International Review of Research in Mental Retardation, 26, 61-91.

White, S. W., Lerner, M. D., McLeod, B. D., Wood, J. J., Ginsburg, G. S., Kerns, C., Ollendick, T., Kendall, P. C., Piacentini, J., Walkup, J., \& Compton, S. (2015a). Anxiety in youth with and without autism spectrum disoder: Examination of factorial equivalence. Behavior Therapy, 46, 40-53.

*White, S. W., Maddox, B. B., \& Panneton, R. K. (2015b). Fear of negative evaluation influences eye gaze in adolescents with autism spectrum disorder: A pilot study. Journal of Autism and Developmental Disorders, 45, 3446-3457.

White, S. W., \& Roberson-Nay, R. (2009). Anxiety, social deficits, and loneliness in youth with autism spectrum disorders. Journal of Autism and Developmental Disorders, 39, 1006-1013.

*Williamson, S., Craig, J., \& Slinger, R. (2008). Exploring the relationship between measures of self-esteem and psychological adjustment among adolescents with Asperger syndrome. Autism : The International Journal of Research and Practice, 12, 391-402.

Wood, J. J., \& Gadow, K. D. (2010). Exploring the nature and function of anxiety in youth with autism spectrum disorders. Clinical Psychology: Science and Practice, 14, 281-292. 